\title{
Pierre M. Conlon, Le siècle des Lumières. Bibliographie chronologique
}

\section{Franco Piva}

\section{Q OpenEdition}

1 Journals

\section{Edizione digitale}

URL: http://journals.openedition.org/studifrancesi/27567

DOI: 10.4000/studifrancesi.27567

ISSN: 2421-5856

\section{Editore}

Rosenberg \& Sellier

\section{Edizione cartacea}

Data di pubblicazione: 31 décembre 2006

Paginazione: 599-600

ISSN: 0039-2944

\section{Notizia bibliografica digitale}

Franco Piva, "Pierre M. Conlon, Le siècle des Lumières. Bibliographie chronologique », Studi Francesi [Online], 150 (L | III) | 2006, online dal 30 novembre 2015, consultato il 08 novembre 2020. URL : http:// journals.openedition.org/studifrancesi/27567 ; DOI : https://doi.org/10.4000/studifrancesi.27567

Questo documento è stato generato automaticamente il 8 novembre 2020.

\section{(c) $(1) \&$}

Studi Francesi è distribuita con Licenza Creative Commons Attribuzione - Non commerciale - Non opere derivate 4.0 Internazionale. 


\title{
Pierre M. Conlon, Le siècle des Lumières. Bibliographie chronologique
}

\author{
Franco Piva
}

\section{NOTIZIA}

Pierre M. Conlon, Le siècle des Lumières. Bibliographie chronologique. Tome XXIII (1788), Genève, Droz, 2005 («Histoire des idées et critique littéraire», 419), pp. XXVII + 457.

1 La prima riflessione che il lettore fa scorrendo questo volume della Bibliographie chronologique du siècle des lumières riguarda l'enorme mole di titoli che esso raccoglie: oltre 4000 per un solo anno, segno evidente non solo della buona salute dell'editoria francese ma anche della vivacità di una cultura che, pur essendo ormai prossima alla fine (o forse proprio per questo) trova modo di esprimersi nelle forme più diverse: da quelle più tradizionali a quelle più moderne. Ampio spazio continua ad avere l'editoria legata alla religione che, nonostante l'azione di sape condotta dai philosophes, continua a coinvolgere la maggior parte dei Francesi e a suscitare il loro interesse: libri di devozione, traduzioni, opere di divulgazione, ma anche di teologia e di polemica. Particolarmente violenta quella suscitata dalla decisione, presa dal re l'anno precedente, di reintegrare i Protestanti nella società civile: accanto al favore di alcuni, queste disposizioni incontrarono la forte reazione di altri, dando luogo ad un dibattito molto intenso e a prese di posizione spesso molto aspre. Anche la letteratura continua ad essere presente, pur se con una spinta creativa meno intensa: Non mancano naturalmente le opere originali (questo è, tra l'altro, l'anno della prima edizione di Paul et Virginie, opera destinata ad uno straordinario successo), ma più intensa appare l'attività di traduzione: dall'inglese naturalmente da cui proviene di tutto (romanzi per lo più, tradotti subito dopo la loro comparsa, talvolta addirittura in due versioni distinte, senza tuttavia escludere opere di natura scientifica), ma anche dalla Germania, nei riguardi della quale l'attenzione dei Francesi si fa anzi sempre più attiva. 
2 Molto più vivo è, tuttavia, il dibattito ideologico e politico in corso, per la verità già da alcuni anni. Per quanto riguarda il primo è da registrare il crescente interesse che $\mathrm{i}$ Francesi dimostrano per Rousseau, oggetto di un'ammirazione sempre più convinta, $\mathrm{e}$ per la sua opera, analizzata con sempre maggiore interesse ed attenzione, a scapito di Voltaire la cui fama tende invece a declinare, e la cui opera suscita sempre più critiche. Per quanto riguarda la situazione politica, ciò che in questo anno provoca le maggiori reazioni è il tentativo, posto in atto da Lomenie de Brienne, di riformare il sistema giudiziario francese, da un lato, per cercare di renderlo più snello ed efficiente, dall'altro per togliere ai vari Parlamenti quel potere politico che essi avevano acquisito nel tempo, e che impediva, di fatto, di apportare all'ordinamento politico ed amministrativo quelle riforme di cui esso aveva bisogno per uscire dalla crisi in cui lo Stato francese stava via via sprofondando. Di fronte alla resistenza opposta da alcuni Parlamenti, il re ricorse anche alla forza, ma alla fine dovette cedere, anticipando la convocazione degli Stati generali, inizialmente prevista per il 1792, per tentare di risolvere almeno l'altro grosso problema dello Stato francese: quello della grave crisi finanziaria in cui si trovava senza inasprire ulteriormente le tasse e i balzelli di cui era già gravato il terzo stato, la cui vita era sempre più difficile, anche a causa delle condizioni climatiche non proprio favorevoli che avevano aggravato una situazione economica già precaria.

Il quadro che emerge dai titoli raccolti in questo volume è quello di un Paese che, all'apparenza vivace e vitale, si trova in realtà sull'orlo di un baratro che lo porterà ad una svolta radicale, alla quale tuttavia il Paese si incammina senza averne, nella maggior parte dei casi, coscienza. Un quadro che il meticoloso lavoro di P.M. Conlon, cui non può non andare la gratitudine di quanti, per un verso o per un altro, s'interessano al Settecento, consente di visitare in ogni suo più recondito aspetto sulla scorta di informazioni precise e facilmente riscontrabili, essendo ogni titolo accompagnato dall'indicazione della biblioteca in cui si può trovare. 